\title{
Two new species of the planthopper genus Eponisiella Emeljanov from China (Hemiptera, Fulgoromorpha, Meenoplidae)
}

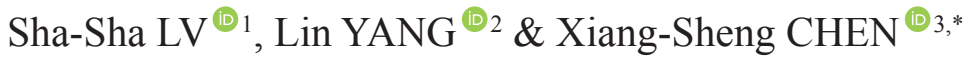 \\ ${ }^{1,2,3}$ Institute of Entomology, Guizhou University, Guiyang, Guizhou 550025, P.R. China. \\ 1,2,3 The Provincial Special Key Laboratory for Development and Utilization of Insect Resources, \\ Guizhou University, Guiyang, Guizhou 550025, P.R. China. \\ *Corresponding author: chenxs3218@163.com \\ ${ }^{1}$ Email: 1s13116322648@163.com \\ 2Email: yanglin6626@163.com \\ ${ }^{1}$ urn:lsid:zoobank.org:author:4E2050EC-EB1E-4A61-8761-BFB96DB5152D \\ ${ }^{2}$ urn:lsid:zoobank.org:author:17FAF564-8FDA-4303-8848-346AB8EB7DE4 \\ ${ }^{3}$ urn:Isid:zoobank.org:author:D9953BEB-30E6-464A-86F2-F325EA2E4B7C
}

\begin{abstract}
Two new species of the genus Eponisiella Emeljanov, 1984 are described and illustrated from China (Guizhou and Shandong Provinces). These are E. dafangensis sp. nov. and E. shandongensis sp. nov., giving the genus eight species in total. A key to the species of Eponisiella is provided as well as a map of their geographic distribution, which is briefly discussed.
\end{abstract}

Keywords. Fulgoroidea, Oriental region, Kermesiinae, taxonomy, morphology.

Lv S.-S., Yang L. \& Chen X.-S. 2021. Two new species of the planthopper genus Eponisiella Emeljanov from China (Hemiptera, Fulgoromorpha, Meenoplidae). European Journal of Taxonomy 767: 83-93. https://doi.org/10.5852/ejt.2021.767.1489

\section{Introduction}

Meenoplidae Fieber, 1872 is a small family of planthoppers (Hemiptera: Fulgoromorpha), established by Fieber (1872), with currently 166 described species in 23 genera respectively counting only for $1.2 \%$ and $0.9 \%$ of the specific and generic diversity of the Fulgoromorpha Evans, 1946 (Bourgoin 2021). The family can be easily recognized from other families by the claval veins of tegmina with a paired or single row of sensory pits, the concave head apically with distinct lateral carinae, and a body length usually less than $5 \mathrm{~mm}$. It contains two subfamilies (Meenoplinae Fieber, 1872 and Kermesiinae Kirkaldy, 1906) mainly distributed throughout the Old World tropics, extending into the eastern Palearctic (Emeljanov 1984; Bourgoin 1997), although being absent from the Nearctic and Neotropical bioregions (Bourgoin 2021). Kermesiinae was first established by Kirkaldy (1906) with the type genus Kermesia Melichar, 1903, and is characterized by the claval veins (Pcu and CuA) merging distally and the clavus with a row of sensory pits on each side of Pcu. Currently the subfamily includes 17 genera and 103 species, while in China, only six genera and 17 species occur (Wilson 1988; Hu \& Yang 1993; Bourgoin 2021). 
Within Kermesiinae, Eponisiella Emeljanov, 1984 is a small genus including six species. It was established by Emeljanov (1984) with three species previously described as Eponisia guttulinervis Matsumura, 1914 from Japan, Nisia suisapana Fennah, 1956 from China (Hubei), and Nisia paludicola Vilbaste, 1968, which was designed as the type species of the genus. Two years later, Tsaur et al. (1986) synonymized Eponisiella paludicola (Vilbaste, 1968) with Eponisiella guttulinervis (Matsumura, 1914) and described E. matsumurai Tsaur, Yang \& Wilson, 1986 from China (Taiwan). Emeljanov (1987) added E. casta Emeljanov, 1987 from Russia, Hu \& Yang (1993) added E. gramina Hu \& Yang, 1993 from China (Jiangsu) and Rahman et al. (2014) described E. andonga Rahman et al., 2014 from Korea.

Herein, two new species, E. dafangensis sp. nov. and E. shandongensis sp. nov. from China, are described and illustrated. As a result, the genus Eponisiella now contains eight species. A key based on morphological characteristics to distinguish the species is provided as well as a map of their geographic distributions.

\section{Material and methods}

The external morphology terminologies follow Bourgoin (1997) and Bourgoin et al. (2015) for venation and Bourgoin (1987) for the male genitalia. Body length is from apex of head to tip of tegmina. The metatibiotarsal formula LT-(T)/Mt1/Mt2 provides the number of spines on the side of the metatibia (LT) - on the apex of metatibia (T), eventually in two groups of internal (Ti) and external (Te) spines separated with a diastema (Ti-Te) / on the apex of first metatarsomere (Mt1) / on the apex of second metatarsomere (Mt2). Biogeographical terminology follows Holt et al. (2013). All measurements are in millimeters $(\mathrm{mm})$. The genital segments were removed from the examined specimens and macerated in $10 \% \mathrm{NaOH}$, washed in water and transferred to glycerin. External morphology and drawings were done under a Leica MZ 12.5 stereo microscope. Photographs were taken using a NIKON SMZ 25 digital camera and multiple layers were stacked using Helicon Focus ver. 6. The photographs and illustrations were imported into Adobe Photoshop ver. 6.0 for plate composition and labeling.

The type specimens are deposited in the Institute of Entomology, Guizhou University, Guiyang, Guizhou Province, China (IEGU).

\section{Results}

\section{Taxonomy}

Class Insecta Linnaeus, 1758

Order Hemiptera Linnaeus, 1758

Infraorder Fulgoromorpha Evans, 1946

Family Meenoplidae Fieber, 1872

Subfamily Kermesiinae Kirkaldy, 1906

Genus Eponisiella Emeljanov, 1984

Eponisiella Emeljanov, 1984: 481.

Eponisiella - Tsaur et al. 1986: 98. — Rahman et al. 2014: 326.

\section{Type species}

Eponisiella guttulinervis (Matsumura, 1914), designated by Tsaur et al. 1986. (= Nisia paludicola Vilbaste, 1968, original designation, synonymized by Tsaur et al. 1986). 


\section{Diagnosis}

Body very small. Head concave apically with a stripe medially. Vertex with two posterolateral areolets at base. Lateral carinae of frons ending at frontoclypeal suture strongly convergent apically. Lateral carinae of postclypeus absent. Pronotum without carina, mesonotum with a weak median carina. Tegmina broadened apically with blackish markings, $\mathrm{MP}_{1+2}$ not branched. Wings with RP not forked. Metatibiotarsal formula: (3+5)-7-5. Male genitalia with pygofer strongly produced in a dorsocaudal angle in lateral view; in caudoventral view, strongly concave medially, each side with a finger-like process with hairs lateroapically.

\section{Distribution}

Japan, Russia, Korea, China (Taiwan, Hubei, Jiangsu, Guizhou, Shandong) (Fig. 21).

\section{Key to species of the genus Eponisiella Emeljanov, 1984}

1. Tegmina with only longitudinal veins darkened, without transverse brown band ........................... 2

- Tegmina with longitudinal veins darkened and transverse brown band .......................................... 3

2. Frons and clypeus with blurred longitudinal stripe E. casta Emeljanov, 1987

- Frons pale yellow and clypeus brown, longitudinal stripe absent (Rahman et al. 2014: fig. 2c) ....... E. andonga Rahman et al., 2014

3. Tegmina with two transverse brown bands apically

- Tegmina with three transverse brown bands apically

4. CuA vein of tegmina without a long brown stripe; only a short brown stripe on longitudinal median vein (MP) before branching (Fennah 1956: fig. 9e)

E. suisapana (Fennah, 1956)

- $\mathrm{CuA}$ vein of tegmina with a long brown stripe; a long brown stripe on longitudinal median vein (MP) before branching, and a short brown stripe on longitudinal median vein after branching

5. Inner side of gonostyli (Fig. 10) concave medially producing an angular production; anal tube (Fig. 10) with bifurcate curved hooks at apex in lateral view; lower part of aedeagus (Figs 10, 12) bifurcate at apex

E. dafangensis sp. nov.

- Inner side of gonostyli medially without an angular production; anal tube without curved hooks at apex in lateral view; lower part of aedeagus not bifurcate at apex (Hu \& Yang 1993: fig. 2)

E. gramina Hu \& Yang, 1993

6. Gonostyli with three bumps near middle in caudoventral view; aedeagus bifurcate (Tsaur et al. 1986: fig. $10 \mathrm{~g}-\mathrm{h})$ E. matsumurai Tsaur et al., 1986

- Gonostyli with one or two bumps near middle in caudoventral view; aedeagus trifurcate . 7

7. Gonostyli with one bump near middle in caudoventral view; anal tube subapically with two productions, bifurcate at apex in lateral view

E. guttulinervis (Matsumura, 1914)

- Gonostyli (Fig. 19) with two bumps near middle and third in caudoventral view; anal tube (Fig. 18) subapically with two productions, not bifurcate at apex in lateral view

E. shandongensis sp. nov. 


\section{Eponisiella dafangensis sp. nov.}

urn:1sid:zoobank.org:act:094B1313-C337-4DDF-9143-6B9ED1829777

Figs $1-2,5-12$

\section{Diagnosis}

The salient features of the new species include: tegmina (Fig. 8) with two transverse brown bands apically; inner side of gonostyli (Fig. 10) concave medially producing an angular production; anal tube in lateral view (Fig. 10) bifurcate with two curved hooks at apex, lateral margins bifurcate at apex in dorsal view (Fig. 7); aedeagus (Figs 10, 12) bifurcate, lower part bifurcate at apex.

\section{Etymology}

The new species is named after its collecting location in the Dafang County (Guizhou Province).

\section{Type material}

\section{Holotype}

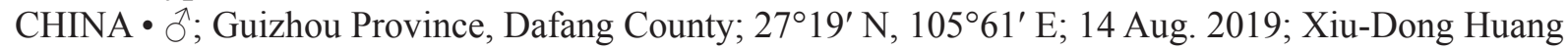
leg.; IEGU.

\section{Paratypes}

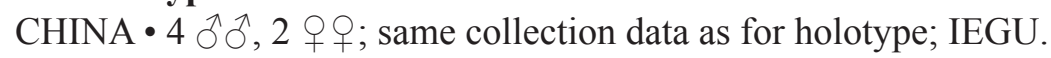

\section{Description}

Measurements. Body length including tegmina: male $2.90-3.11 \mathrm{~mm}(\mathrm{~N}=5)$, female $3.10-3.21 \mathrm{~mm}$ $(\mathrm{N}=2)$.
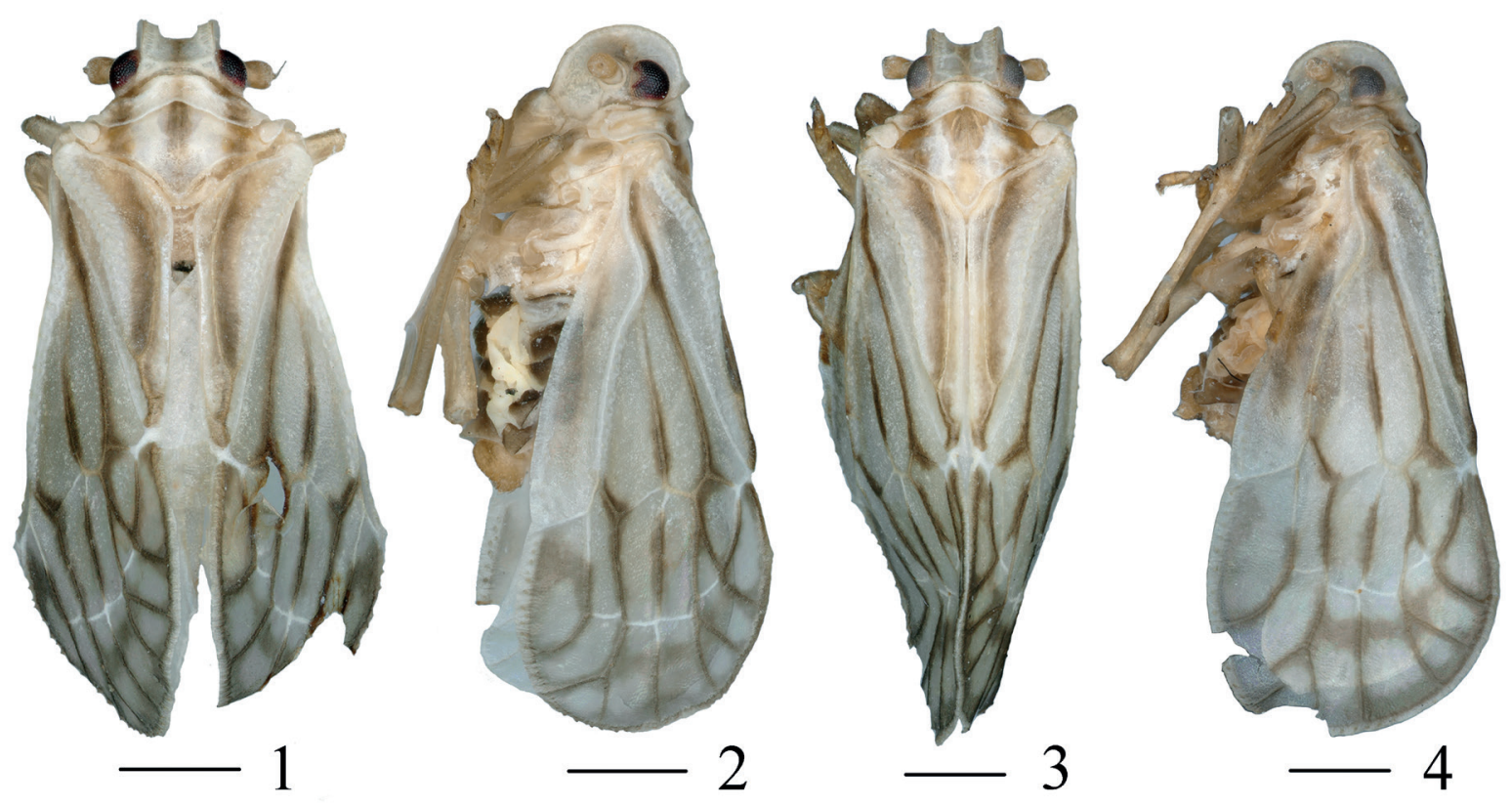

Figs 1-4. Eponisiella dafangensis sp. nov. and Eponisiella shandongensis sp. nov. 1-2. E. dafangensis sp. nov., đ̃, holotype (IEGU), habitus. 1. Dorsal view. 2. Lateral view. 3-4. E. shandongensis sp. nov., $\lambda$, holotype (IEGU), habitus. 3. Dorsal view. 4. Lateral view. Scale bars $=0.5 \mathrm{~mm}$. 

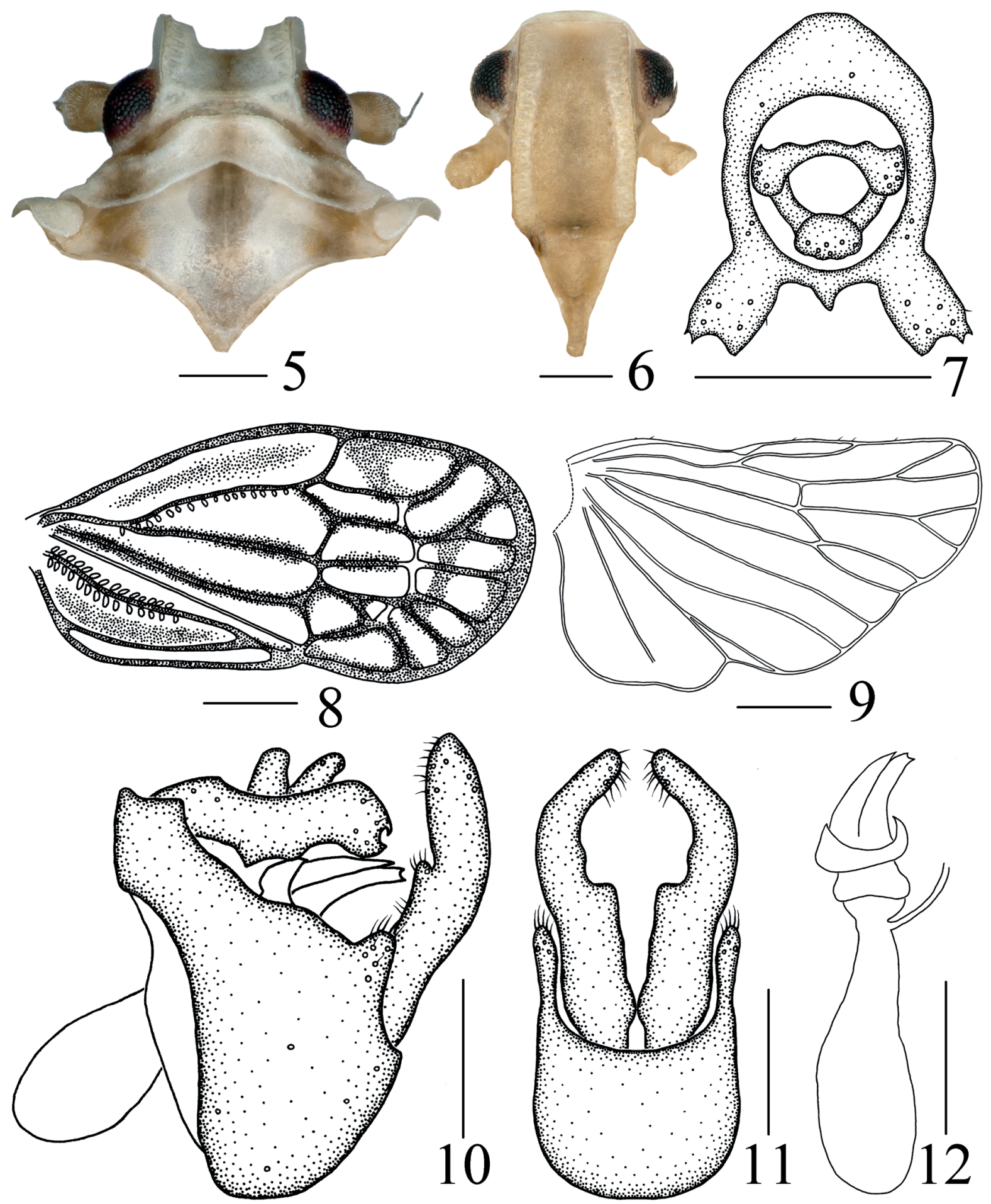

Figs 5-12. Eponisiella dafangensis sp. nov., $\widehat{\jmath}$, holotype (IEGU). 5. Head and thorax, dorsal view. 6. Frons, ventral view. 7. Anal tube, dorsal view. 8. Tegmina. 9. Wing. 10. Pygofer, lateral view. 11. Gonostyli and pygofer, caudoventral view. 12. Aedeagus, left lateral view. Scale bars: $5-7,10$ $12=0.2 \mathrm{~mm} ; 8-9=0.5 \mathrm{~mm}$. 
Coloration. General color grayish white (Figs 1-2). Eyes blackish brown. Frons pale brown, with weak blackish stripe in middle. Clypeus and antenna pale brown. Vertex, pronotum and mesonotum with brown stripe in middle, pronotum and mesonotum with two yellowish-brown patches on both sides. Tegmina with longitudinal veins and adjacent parts of membrane with dark patterns, with two transverse brown bands apically. Wings waxy white with pale veins.

HEAD AND thorax. Head (Figs 1, 5) significantly narrower than pronotum. Vertex shorter in middle than wide at base $(1: 2.32)$, posterior margin slightly convex, with two triangular posterolateral areolets widely separated from each other, not nearly approaching in middle line. Frons (Fig. 6) approximately rectangular, without median carina, longer in middle line than wide at widest portion (about 1.66:1), lateral carinae with dense row of sensory pits along outer margin. Clypeus (Fig. 6) without lateral carinae, elevated medially, median carina present. Frontoclypeal suture nearly straight. Rostrum elongate, surpassing hind-coxae. Pronotum (Fig. 5) short, wider than maximum width of head (including eyes) (1.36:1), lateral carinae sinuate, median carina absent. Mesonotum (Fig. 5) about $4.08 \times$ as long as pronotum in midline, with weak median carina. Tegmina (Fig. 8) broadened apically, longer than maximal width (2.02:1). A2 of wing (Fig. 9) not reaching margin. Metatibiotarsal formula: (3+5)-7-5.

Male Genitalia. Pygofer (Figs 10-11) in lateral view with dorsocaudal angle strongly produced; in caudoventral view, strongly concave medially, each side with finger-like process with hairs lateroapically, slightly curved outwardly. Anal tube stout (Figs 7, 10) in lateral view, bifurcate curved hooks at apex, ventral margin waved; in dorsal view, bifurcate, lateral margins bifurcate at apex, anal style sets near base. Aedeagus (Figs 10,12) bifurcate in lateral view, almost as long as anal tube, lower part of aedeagus slightly blunt, bifurcate at apex. Gonostyli (Figs 10-11) in lateral view, slightly curved at middle, inner side concave medially producing angular production; in caudoventral view, near middle to apex much narrower than other part, curved inwards with two bumps.

\section{Distribution}

China (Guizhou) (Fig. 21).

\section{Remarks}

This species is similar to Eponisiella gramina Hu \& Yang, 1993, but differs from the latter in: (1) inner side of gonostyli concave medially producing an angular production (inner side of gonostyli almost equal in width without an angular production in E. gramina); (2) anal tube in lateral view branched at apex (anal tube in lateral view unbranched at apex in E. gramina); (3) lower part of aedeagus bifurcate at apex (lower part of aedeagus not bifurcate at apex in E. gramina).

Eponisiella shandongensis sp. nov. urn:lsid:zoobank.org:act:A24188AA-9CDC-4642-9A1A-20B862BA6AB5

Figs 3-4, 13-20

\section{Diagnosis}

The salient features of the new species include: tegmina (Fig. 16) with three transverse brown bands apically; ventral and dorsal margins of anal tube (Fig. 18) each with a dentate productions at apex in lateral view; gonostyli (Fig. 19) with two bumps near middle and third in caudoventral view; aedeagus (Figs 18, 20) trifurcate.

\section{Etymology}

The new species is named after its collecting location in the Shandong Province. 


\section{Type material}

\section{Holotype}

CHINA • O'; $^{\prime}$ Shandong Province, Yellow River Delta Nature Reserve; $37^{\circ} 72^{\prime}$ N, $118^{\circ} 95^{\prime}$ E; 4 Aug. 2014; Wei-Bin Zheng leg.; IEGU.

\section{Paratypes}

CHINA • 2 + 9 ; same collection data as for holotype; IEGU.

\section{Description}

Measurements. Body length including tegmina: male $3.01 \mathrm{~mm}(\mathrm{~N}=1)$, female $3.10-3.14 \mathrm{~mm}(\mathrm{~N}=2)$.

Coloration. General color grayish white (Figs 3-4). Eyes grayish brown. Frons pale brown, with weak brownish stripe in middle. Clypeus and antenna yellowish-brown. Vertex, pronotum and mesonotum with yellowish-brown stripe in middle, pronotum and mesonotum with two ocherous patches on both sides. Tegmina with longitudinal veins and adjacent parts of membrane with dark patterns, with three transverse brown bands apically. Wings waxy white with pale veins.

Head and thorax. Head (Figs 3, 13) significantly narrower than pronotum. Vertex shorter in middle than wide at base $(1: 2.11)$, posterior margin slightly convex, with two triangular posterolateral areolets widely separated from each other, not nearly approaching in middle line. Frons (Fig. 14) approximately rectangular, without median carina, longer in middle line than wide at widest portion (about $1.61: 1$ ), lateral carinae with dense row of sensory pits along outer margin. Clypeus (Fig. 14) without lateral carinae, elevated medially, median carina present. Frontoclypeal suture nearly straight. Rostrum elongate, surpassing hind-coxae. Pronotum (Fig. 13) short, wider than maximum width of head (including eyes) (1.38:1), lateral carinae sinuate, median carina absent. Mesonotum (Fig. 13) about $4.83 \times$ as long as pronotum in midline, with weak median carina. Tegmina (Fig. 16) broadened apically, longer than maximal width (2.03:1). A2 of wing (Fig. 17) not reaching margin. Metatibiotarsal formula: (3+5)-7-5.

Male Genitalia. Pygofer (Figs 18-19) in lateral view with dorsocaudal angle strongly produced; in caudoventral view, strongly concave medially, each side with finger-like process with hairs lateroapically, slightly curved outwardly. Anal tube stout (Figs 15,18) in lateral view, ventral margin of anal tube waved, apex of ventral and dorsal margins each with dentate productions; in dorsal view, bifurcate; anal style short. Aedeagus (Figs 18,20) trifurcate in lateral view, little shorter than anal tube, lower part of aedeagus slightly blunt, bifurcate at apex, upper one bends to form protrusion. Gonostyli (Figs 1819) in lateral view, curved at middle, inner side concave medially producing angular production; in caudoventral view, two bumps near middle and third, respectively.

\section{Distribution}

China (Shandong) (Fig. 21).

\section{Remarks}

This species is similar to E. matsumurai Tsaur, Yang \& Wilson, 1986, but differs from the latter in: (1) aedeagus trifurcate (aedeagus bifurcate in E. matsumurai); (2) gonostyli with two bumps near middle and third in caudoventral view (gonostyli with three bumps near middle in caudoventral view in E. matsumurai); (3) inner side of gonostyli medially producing an angular production (inner side of gonostyli concave medially without an angular production in E. matsumurai). 

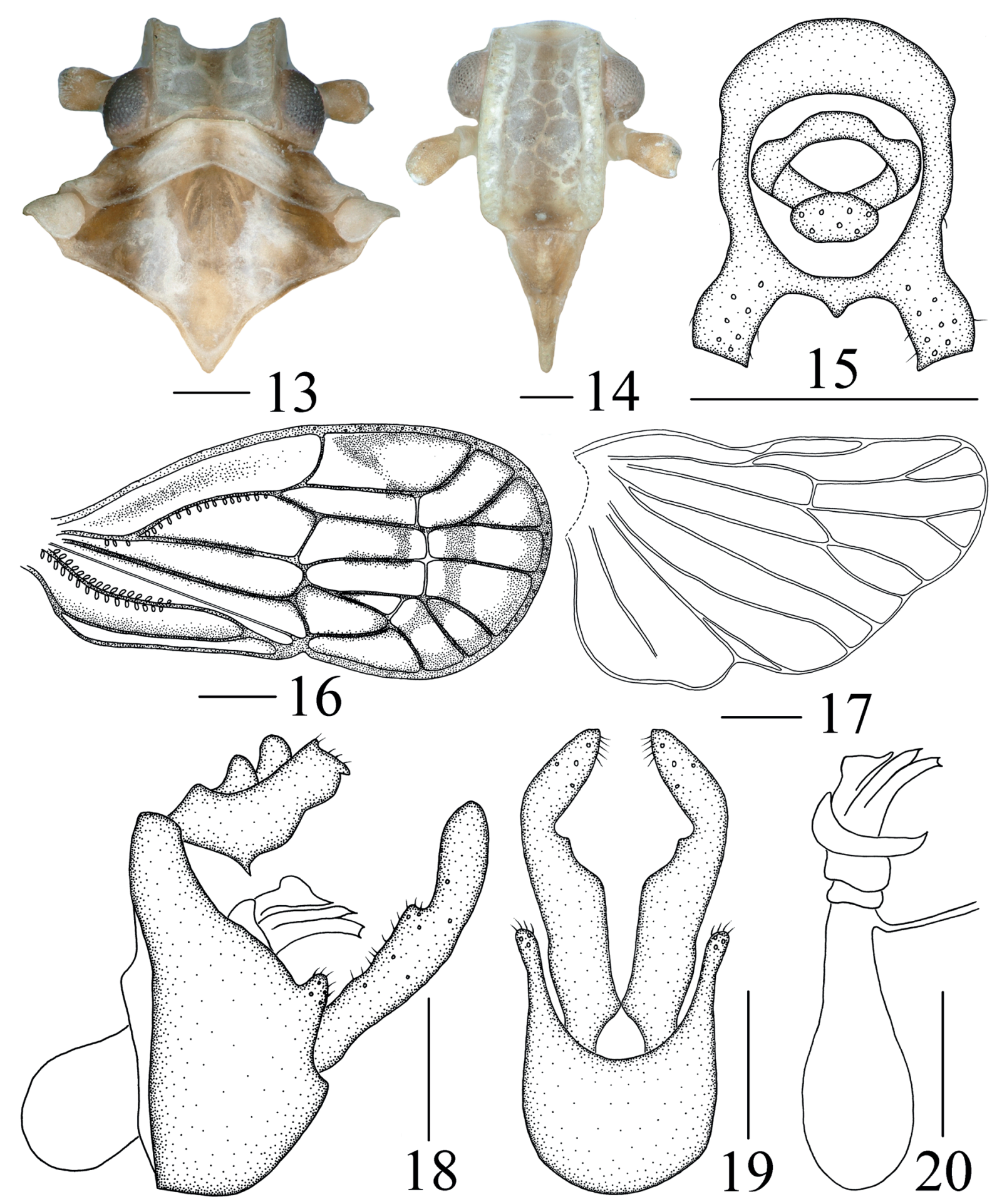

Figs 13-20. Eponisiella shandongensis sp. nov., $\widehat{\jmath}$, holotype (IEGU). 13. Head and thorax, dorsal view. 14. Frons, ventral view. 15. Anal tube, dorsal view. 16. Tegmina. 17. Wing. 18. Pygofer, lateral view. 19. Gonostyli and pygofer, caudoventral view. 20. Aedeagus, left lateral view. Scale bars: $13-15$, $18-20=0.2 \mathrm{~mm} ; 16-17=0.5 \mathrm{~mm}$. 


\section{Discussion}

As for many planthoppers and particularly for the family Meenoplidae, host plants remain very poorly known. In Eponisiella, only E. gramina was noticed on Miscanthus sacchariflorus (Maxim.) Benth. \& Hook.f. ex Franch. (Poales, Poaceae) (Hu \& Yang 1993). No any other etho-ecological data are currently known for the genus.

The discovery of these two new species confirms the geographic distribution of the genus (Fig. 21) into the Sino-Japanese realm (E. shandongensis sp. nov.) where it appears to be the more diverse and in the Oriental one (E. dafangensis sp. nov.), this later fills the distribution gap with the isolated species $E$. andonga described from Korea. However, it also extends the distribution range of the genus to the north into the Palearctic realm (E. guttulinervis, E. casta). There is no doubt that the highly diverse natural conditions in China, particularly in the Oriental realm part, will bring new species of the genus to be described in the future.

\section{Acknowledgments}

The authors sincerely thank Prof. Thierry Bourgoin (Institut de Systématique, Évolution, Biodiversité, Muséum national d'histoire naturelle, Sorbonne Universités, Paris, France) for reviewing the manuscript carefully. The authors are grateful to the specimen collectors for their hard work in the field collections. This research was supported by the National Natural Science Foundation of China (grant no. 32060343, 31472033); the Science and Technology Support Program of Guizhou Province (grant no. 20201Y129); the Program of Excellent Innovation Talents, Guizhou Province (grant no. 20154021).

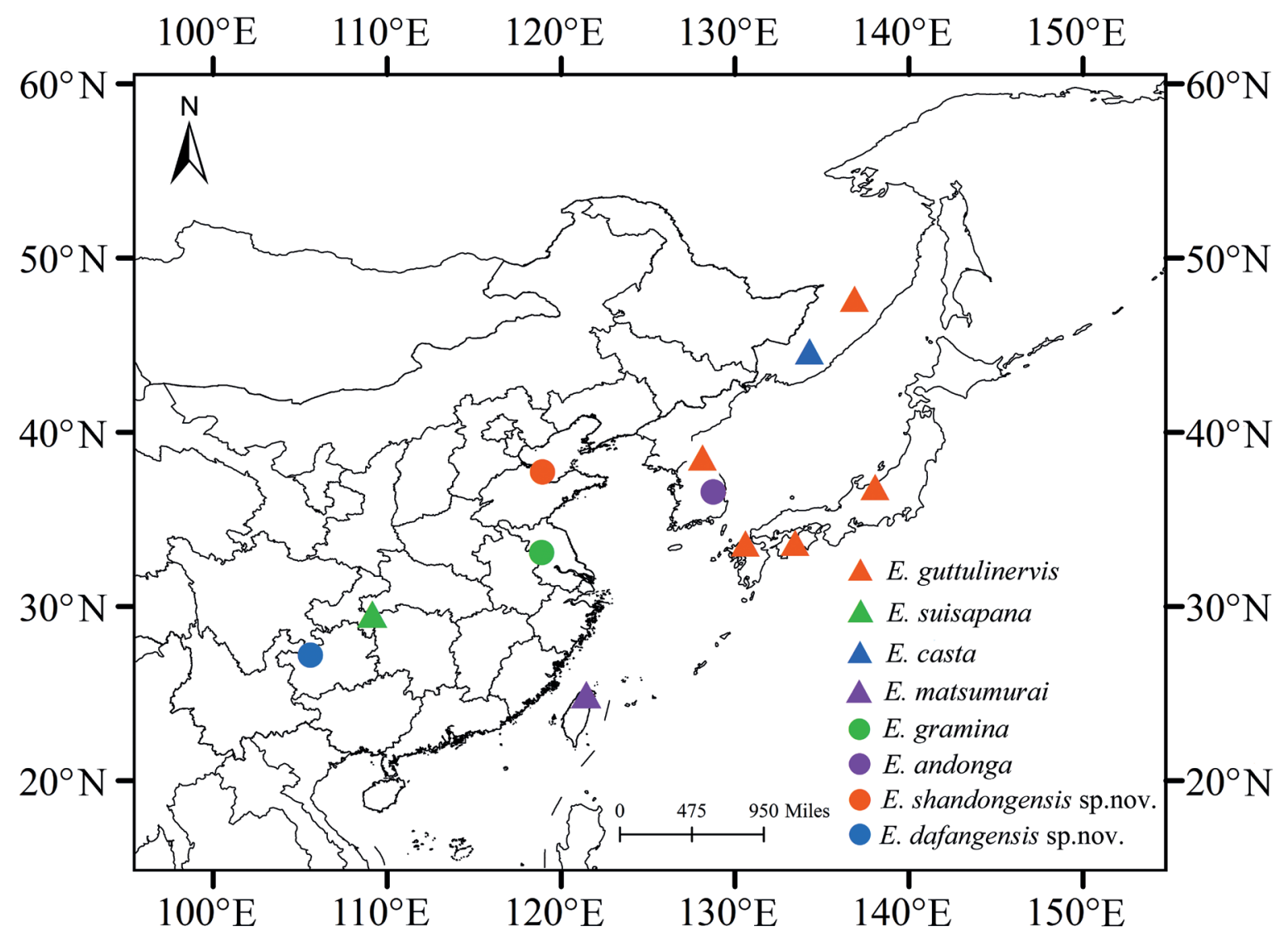

Fig 21. Geographic distribution of species of Eponisiella Emeljanov, 1984. 


\section{References}

Bourgoin T. 1987. A new interpretation of the homologies of the Hemiptera male genitalia, illustrated by the Tettigometridae (Hemiptera, Fulgoromorpha). In: Vidano C. \& Arzone A. (eds) Proceedings of the $6^{\text {th }}$ Auchenorrhyncha Meeting, Turin, Italy, 7-11 Sep. 1987: 113-120. Consiglio Nazionale delle Ricerche, Turin, Italy.

Bourgoin T. 1997. The Meenoplidae (Hemiptera, Fulgoromorpha) of New Caledonia, with a revision of the genus Eponisia Matsumura, 1914, and new morphological data on forewing venation and wax plate areas. Memoires du Museum national d'histoire naturelle 171: 197-249.

Bourgoin T. 2021. FLOW (Fulgoromorpha Lists On the Web): a world knowledge base dedicated to Fulgoromorpha. Version 8. Available from http://hemiptera-databases.org/flow/ [accessed 8 Apr. 2021].

Bourgoin T., Wang R.R., Asche M., Hoch H., Soulier-Perkins A., Stroiñsiki A., Yap S. \& Szwedo J. 2015. From micropterism to hyperpterism recognition strategy and standardized homology-driven terminology. Zoomorphology 134 (1): 63-77. https://doi.org/10.1007/s00435-014-0243-6

Emeljanov A.F. 1984. A contribution to knowledge of the families Kinnaridae and Meenoplidae (Homoptera, Fulgoroidea). Entomologicheskoie Obozrenie 3: 464-483.

Emeljanov A.F. 1987. New species of cicads (Homoptera, Cicadina) from the Far East and Eastern Siberia. In: Kapustina O.G. (ed.) Taksonomiia nasekomykh Sibiri i Dal'nego Vostoka SSR.: 22-30. Dalnauka, Vladivostok.

Fennah R.G. 1956. Fulgoroidea from southern China. In: Kessel E.L. (ed.) Proceedings of the California Academy of Sciences. San Francisco 28 (4): 441-527. California Academy of Science, California, USA. Available from https://www.biodiversitylibrary.org/page/15656827\#page/453/mode/1up [accessed 10 Sep. 2021].

Fieber F.X. 1872. Katalog der Europäischen Cicadinen, nach Originalien mit Benützung der Neuesten Literatur. Carl Gerold's Sohn, Vienna.

Holt B.G., Lessard J.P., Borregaard M.K., Fritz S.A., Araújo M.B., Dimitrov D., Fabre P.H., Graham C.H., Graves G.R., Jønsson K.A., Nogués-Bravo D., Wang Z., Whittaker R.J., Fjeldså J. \& Rahbek C. 2013. An update of Wallace's zoogeographic regions of the world. Science 339: 74-78.

https://doi.org/10.1126/science.1228282

Hu C.L. \& Yang L.F. 1993. List of Meenoplid species of China with one new species (Homoptera: Fulgoroidea). Entomotaxonomia 15 (1): 35-40.

Kirkaldy G.W. 1906. Leafhoppers and their natural enemies. (Pt. IX Leafhoppers. Hemiptera). Bulletin of the Hawaiian Sugar Planters' Association Experiment Station. Division of Entomology. Honolulu 1 (9): 271-479.

Rahman M.A., Kwon Y.J. \& Suh S.J. 2014. Taxonomic revision of the subfamily Kermesiinae (Hemiptera: Meenoplidae) from Korea. Entomological Research 44 (6): 323-330.

https://doi.org/10.1111/1748-5967.12082

Tsaur S.C., Yang C.T. \& Wilson M.R. 1986. Meenoplidae of Taiwan (Homoptera: Fulgoroidea). Journal of the National Taiwan Museum 81-118.

Wilson M.R. 1988. Afronisia, a new African genus of Meenoplidae (Homoptera: Fulgoroidea). Great Basin Naturalist Memoirs 12: 324-334. https://doi.org/10.5962/bhl.part.10988 
Manuscript received: 9 April 2021

Manuscript accepted: 27 July 2021

Published on: 14 September 2021

Topic editor: Nesrine Akkari

Section editor: Christopher H. Dietrich

Desk editor: Eva-Maria Levermann

Printed versions of all papers are also deposited in the libraries of the institutes that are members of the EJT consortium: Muséum national d'histoire naturelle, Paris, France; Meise Botanic Garden, Belgium; Royal Museum for Central Africa, Tervuren, Belgium; Royal Belgian Institute of Natural Sciences, Brussels, Belgium; Natural History Museum of Denmark, Copenhagen, Denmark; Naturalis Biodiversity Center, Leiden, the Netherlands; Museo Nacional de Ciencias Naturales-CSIC, Madrid, Spain; Real Jardín Botánico de Madrid CSIC, Spain; Zoological Research Museum Alexander Koenig, Bonn, Germany; National Museum, Prague, Czech Republic. 